\title{
Estimation of the genome sizes of the chigger mites Leptotrombidium pallidum and Leptotrombidium scutellare based on quantitative PCR and k-mer analysis
}

Ju Hyeon Kim', Jong Yul Roh², Deok Ho Kwon ${ }^{3}$, Young Ho Kim³, Kyungjae A Yoon', Seungil Yoo ${ }^{4}$, Seung-Jae Noh ${ }^{4}$, Junhyung Park ${ }^{4}$ E-hyun Shin ${ }^{2}$, Mi-Yeoun Park ${ }^{2}$ and Si Hyeock Lee ${ }^{1,3^{*}}$

\begin{abstract}
Background: Leptotrombidium pallidum and Leptotrombidium scutellare are the major vector mites for Orientia tsutsugamushi, the causative agent of scrub typhus. Before these organisms can be subjected to whole-genome sequencing, it is necessary to estimate their genome sizes to obtain basic information for establishing the strategies that should be used for genome sequencing and assembly.

Method: The genome sizes of L. pallidum and L. scutellare were estimated by a method based on quantitative real-time PCR. In addition, a k-mer analysis of the whole-genome sequences obtained through Illumina sequencing was conducted to verify the mutual compatibility and reliability of the results.

Results: The genome sizes estimated using GPCR were $191 \pm 7 \mathrm{Mb}$ for L. pallidum and $262 \pm 13 \mathrm{Mb}$ for L. scutellare. The k-mer analysis-based genome lengths were estimated to be $175 \mathrm{Mb}$ for L. pallidum and $286 \mathrm{Mb}$ for $L$. scutellare. The estimates from these two independent methods were mutually complementary and within a similar range to those of other Acariform mites.

Conclusions: The estimation method based on qPCR appears to be a useful alternative when the standard methods, such as flow cytometry, are impractical. The relatively small estimated genome sizes should facilitate whole-genome analysis, which could contribute to our understanding of Arachnida genome evolution and provide key information for scrub typhus prevention and mite vector competence.
\end{abstract}

Keywords: Leptotrombidium pallidum, Leptotrombidium scutellare, Genome size, Scrub typhus, Rickettsiosis

\section{Background}

Scrub typhus, which is also known as chigger-borne rickettsiosis, is an acute, febrile disease caused by an obligate intracellular bacterium, Orientia tsutsugamushi. This pathogen causes fever, rash, eschar formation and pneumonitis and the symptoms can vary from mild to fatal [1]. If not treated with appropriate antibiotics, mortality rates by scrub typhus are reported to be in $1 \%$ to $40 \%$, depending on area and O. tsutsugamushi strain [2]. This

\footnotetext{
* Correspondence: shlee22@snu.ac.kr

'Department of Agricultural Biotechnology, Seoul National University, Seoul 151-921, Korea

${ }^{3}$ Research Institute of Agriculture and Life Sciences, Seoul National University, Seoul 151-921, Korea

Full list of author information is available at the end of the article
}

disease is distributed extensively from the Asia-Pacific region, including Japan, Korea, China, India, Pakistan, the southwestern Pacific islands, and Australia, to the eastern part of Russia [3]. More than one million cases of scrub typhus are reported every year and more than one billion people are exposed to the risk of infection [4].

Humans acquire the disease through a bite from infected larval mites of the family Trombiculidae known as chiggers. Trombiculid mites are very small $(0.2-0.4 \mathrm{~mm})$ and usually inhabit grassy and weedy areas. Chigger is the only parasitic life stage that bites hosts and transmits the disease because other stages, such as nymph and adult, do not feed on hosts [5]. Vertebrate animals, mostly grounddwelling rodents, are the natural hosts for chiggers, 
whereas humans are an incidental host. The chigger pierces the host's skin with its sharp mouthparts and injects digestive enzymes, thereby dissolving tissues of the host for ingestion [5]. Among trombiculid mites, some species belonging to the genus Leptotrombidium are known to transmit O. tsutsugamushi [6], but the major vector species differs from country to country. Leptotrombidium pallidum is widely distributed in Korea [7,8], Japan [3,9-11], and Russia [3,11] and is the primary vector mite in the Korean Peninsula $[8,12,13]$ and Japan [1,14]. Leptotrombidium scutellare, which is also distributed in Korea [7,8], Japan [3,9-11], China [15], Thailand [3,16], and Malaysia [3,17], serves as the predominant transmission vector in the southern part of Korea [8,13], Japan $[1,14,18]$, and northern China [15]. Recent studies have reported that Leptotrombidium mites carry other pathogens, such as hantavirus [19] and Bartonella tamiae, the causative agent of human bartonellosis [20], suggesting that these mites may serve as vectors for a wider variety of pathogens than has been commonly expected. Despite their medical importance, little molecular information on Leptotrombidium mites is available to date. In addition, the molecular and genetic bases of their vector competence are unknown, and there are no available efficient methods for their control.

The whole-genome sequencing of the Leptotrombidium mite would provide fundamental genetic information for understanding vector competence, discovering new target sites for novel acaricides and repellents, and eventually designing efficient measures to prevent scrub typhus. In addition to the completed genomes of Homo sapiens [21] as the host and O. tsutsugamushi [22] as the pathogen, genomic information of Leptotrombidium mite vectors would enable an understanding of the mite vector-hostpathogen interactions. Comparative genomic and transcriptomic analyses between the two Leptotrombidium species would eventually provide basic information on how the differences in their genomic (or transcriptomic) components contribute to the phenotypic differences (i.e., biological and ecological differences) and on what conserved molecular genetic natures are commonly responsible for their vector competence. Prior to the genome sequencing of $L$. pallidum and $L$. scutellare, however, an accurate estimation of their genome size is necessary to ensure sufficient sequencing coverage, particularly if the genome sequencing is conducted through next-generation sequencing (NGS) methods, and to provide a firm reference for genome assembly.

Although flow cytometry is regarded as a standard method for the prediction of the genome size of multicellular organisms [23,24], it is not applicable to all arthropods, particularly if the body size is too small to obtain a sufficient amount of genetic material or if it is difficult to obtain a sufficient number of cells from the body preparations $[25,26]$. As an alternative, a method for the estimation of the genome size based on quantitative real-time PCR (qPCR) was developed [27] and was determined to be reliable and useful for predicting the genome sizes of several arthropods, including Musca domestica [28], Metaseiulus occidentalis [26], Sarcoptes scabiei, Psoroptes ovis, Dermatophagoides pteronyssinus [25], and Cotesia plutellae [29].

In this study, the genome sizes of L. pallidum and L. scutellare, as vector mites of scrub typhus, were estimated by qPCR. To examine the validity and accuracy of the method, we used three arthropods with their genome analysis completed, namely Drosophila melanogaster, Apis mellifera, and Tetranychus urticae, as internal references. In addition, the genome size was also estimated through the k-mer analysis of the Illumina sequencing reads to mutually confirm the results.

\section{Methods}

\section{L. pallidum and $L$. scutellare}

To collect L. pallidum, Sharman traps baited with crackers and peanut butter were set for wild black-striped mice, Apodemus agrarius, on grassy areas near a stream in Cheorwon-gun, Gangwon province, South Korea. The traps were laid out in the late afternoon and retrieved the following morning. All of the ectoparasites on the collected mice were harvested, L. pallidum was identified and isolated through microscopic inspection. The collected $L$. palladium larvae were directly used for genomic DNA isolation. The black-striped mice were captured and handled based on ethical procedures and scientific care according to the animal use protocol that had been reviewed and approved by the Korea Center for Disease Control \& PreventionInstitutional Animal Care and Use Committee (KCDCIACUC; KCDC-046-13-2A).

Laboratory strains of L. pallidum and L. scutellare have been maintained for eight generations and one generation, respectively, in the rearing facility of the Korea Centers for Disease Control and Prevention, Osong, Korea. Both L. pallidum and L. scutellare have been reared in rearing chambers containing a charcoal-plaster mixture (calcium sulfate hemihydrate and charcoal powder, 9:1) and fed eggs of Sinella curviseta.

\section{Cloning of single copy genes}

The total RNA from nine L. pallidum and five L. scutellare females reared in the laboratory was extracted using $100 \mu \mathrm{l}$ of TRI reagent (MRC, Cincinnati, OH, USA) according to the manufacturer's protocol. The first-strand cDNA was synthesized from the DNase I (Takara, Japan)-treated total RNA using SuperScript III reverse transcriptase (Invitrogen, Carlsbad, CA, USA) and used as the PCR template. The degenerate primers were designed from conserved amino acid regions of two putative single copy genes, namely elongation factor $1 \alpha(E F 1 \alpha)$ and ribosomal protein S3 (RpS3), across 
various mite species. The primer sets used for the PCR analysis are provided in Table 1 . The PCR was conducted in a DNA Engine Peltier Thermal Cycler (BioRad, Richmond, CA, USA) using the following cycling conditions: a single denaturation cycle at $95^{\circ} \mathrm{C}$ for 2 min and 35 cycles of $95^{\circ} \mathrm{C}$ for $15 \mathrm{~s}, 55^{\circ} \mathrm{C}(\mathrm{EF} 1 \alpha)$ or $45^{\circ} \mathrm{C}(\mathrm{RpS} 3)$ for $20 \mathrm{~s}$, and $68^{\circ} \mathrm{C}$ for $1 \mathrm{~min}$. The PCR products of appropriate sizes were excised from agarose gels, purified with a QIAquick PCR Purification Kit (Qiagen, Valencia, CA, USA), and then cloned into the pGEM-T easy vector (Promega, Madison, WI, USA).

\section{Extraction of genomic DNA}

The genomic DNA (gDNA) from $170 \mathrm{~L}$. pallidum larvae and $15 \mathrm{~L}$. scutellare female adults was extracted and used for qPCR. The gDNA from 10 female $D$. melanogaster, a single worker A. mellifera, and 100 female T. urticae were also extracted and used as internal controls. The DNA extraction was performed using the Qiagen DNeasy Blood and Tissue Kit (Qiagen, Valencia, CA, USA) according to the manufacturer's instructions. After extraction, the gDNA was treated with $20 \mu \mathrm{l}$ of proteinase $\mathrm{K}$ (Qiagen, $0.5 \mathrm{mg} / \mathrm{ml}$ ) and $2 \mu \mathrm{l}$ of RNase A (Qiagen, $0.2 \mathrm{mg} / \mathrm{ml}$ ) to remove any protein and RNA contamination, respectively. The DNA was eluted with $10 \mathrm{mM}$ Tris and $0.1 \mathrm{mM}$ EDTA buffer ( $\mathrm{pH} 8.5$ ), and aliquots were stored at $-20^{\circ} \mathrm{C}$. The quality and concentration of the gDNA was determined using a NanoDrop spectrophotometer (NanoDrop Technologies, Wilmington, DE, USA) and by agarose gel electrophoresis using a mass ladder (Invitrogen, Carlsbad, CA, USA).

\section{Preparation of standard DNA}

The gDNA fragments of EF1 $\alpha$ and RpS3 for L. pallidum and L. scutellare and of RpS3 for D. melanogaster, A.

Table 1 Primers used in this study

\begin{tabular}{|c|c|c|c|c|c|}
\hline Purpose & Species & Gene & & Sequence $\left(5^{\prime}\right.$ to $\left.3^{\prime}\right)$ & Product size (bp) \\
\hline \multirow[t]{2}{*}{ Cloning } & $\begin{array}{l}\text { Leptotrombidium pallidum } \\
\text { Leptotrombidium scutellare }\end{array}$ & EF1a & $\begin{array}{l}F^{a} \\
R^{b}\end{array}$ & $\begin{array}{l}\text { TATTGATGCTCCTGGTCACAG } \\
\text { GAATTTGCAAGCAATGTGAGC }\end{array}$ & 850 \\
\hline & & RpS3 & $\begin{array}{l}F \\
R\end{array}$ & $\begin{array}{l}\text { GARGAYGGNTAYTCHGGB } \\
\text { CATRAYYTTNACYTTRATDCC }\end{array}$ & 438 \\
\hline \multirow[t]{7}{*}{ Standard } & Drosophila melanogaster & RpS3 & $\begin{array}{l}\mathrm{F} \\
\mathrm{R}\end{array}$ & $\begin{array}{l}\text { CACGTTCCGATTCGACGTC } \\
\text { CACAACGGACACATTGTCGG }\end{array}$ & 925 \\
\hline & Apis mellifera & RpS3 & $\mathrm{F}$ & CTCGTGAACTGTCAGAAGATG & 794 \\
\hline & & & $\mathrm{R}$ & CTGCAAGTGGTATTGGTTGTG & \\
\hline & Tetranychus urticae & RpS3 & $\mathrm{F}$ & TAGACGAATTCCTTCGTCGAG & 553 \\
\hline & & & $\mathrm{R}$ & AGAAACGTTGTCAGGTAATGGT & \\
\hline & $\begin{array}{l}\text { Leptotrombidium pallidum } \\
\text { Leptotrombidium scutellare }\end{array}$ & EF1a & $\begin{array}{l}F \\
R\end{array}$ & $\begin{array}{l}\text { TTGATGCTCCTGGTCACAGA } \\
\text { GCAAGCAATGTGAGCAGTGT }\end{array}$ & 842 \\
\hline & & RpS3 & $\begin{array}{l}F \\
R\end{array}$ & $\begin{array}{l}\text { ATCATCATTCTCGCCACGCG } \\
\text { CTTGTCGCAGTAACACATGCC }\end{array}$ & 447 \\
\hline \multirow[t]{14}{*}{$\mathrm{qPCR}$} & Drosophila melanogaster & RpS3 & $\mathrm{F}$ & CATTGAGTTGTACGCCGAGA & 127 \\
\hline & & & $\mathrm{R}$ & ATGTAGCGGAGCACACCATAG & \\
\hline & Apis mellifera & RpS3 & $\mathrm{F}$ & GTTGTGAAGTGGTTGTTAGTG & 132 \\
\hline & & & $\mathrm{R}$ & GAAGTACATGACGAGTTGCAG & \\
\hline & Tetranychus urticae & RpS3 & $\mathrm{F}$ & ATGTGAAGTTGTCGTTTCCGG & 96 \\
\hline & & & $\mathrm{R}$ & TTACAAGGGTCACCAGCGTG & \\
\hline & Leptotrombidium pallidum & EF1a & $\mathrm{F}$ & GTTAAGGAATTGCGCAGAGG & 123 \\
\hline & & & $\mathrm{R}$ & GTAACCGTTGGCGATTTGTC & \\
\hline & & RpS3 & $\mathrm{F}$ & TCTGACAGAGGCTTGTGTGC & 127 \\
\hline & & & $\mathrm{R}$ & AGCCTITCGCTCCAGATTCC & \\
\hline & Leptotrombidium scutellare & EF1a & $\mathrm{F}$ & CCGGAGATTGGAACGAAAGG & 120 \\
\hline & & & $\mathrm{R}$ & TGGACACAACTGAACCACCC & \\
\hline & & RpS3 & $\mathrm{F}$ & GCACAATGCGAGTCTCTTCG & 111 \\
\hline & & & $\mathrm{R}$ & GACTTCGCAACCTITCGCTC & \\
\hline
\end{tabular}


mellifera, and T. urticae were generated by PCR using the extracted gDNA samples as templates and individual primer sets (Table 1). The PCR assays were conducted with $0.5 \mu \mathrm{M}$ forward and reverse primers, $250 \mu \mathrm{M}$ dNTPs, 10 ng gDNA template, and $1 \mathrm{U}$ of Advantage 2 DNA polymerase mix (Clontech, Palo Alto, CA, USA) in a total volume of $20 \mu \mathrm{l}$. The PCR protocol consisted of an initial denaturation step of $95^{\circ} \mathrm{C}$ for $2 \mathrm{~min}$ followed by 35 cycles of $95^{\circ} \mathrm{C}$ for $15 \mathrm{~s}, 55^{\circ} \mathrm{C}(\mathrm{EF} 1 \alpha)$ or $45^{\circ} \mathrm{C}(\mathrm{RpS} 3)$ for $20 \mathrm{~s}$, and $68^{\circ} \mathrm{C}$ for $1 \mathrm{~min}$. The PCR products were confirmed by agarose gel electrophoresis, purified using a QIAquick Gel Extraction Kit (Qiagen, Valencia, CA, USA), and then cloned into the pGEM-T easy vector (Promega, Madison, WI, USA). The positive plasmids confirmed by sequencing were linearized with Sall (Koschem, Seoul, Korea), purified, and quantified using the same method described above. Seven serial dilutions of the linearized plasmids ranging from $200 \mathrm{pg} / \mu \mathrm{l}$ to $0.2 \mathrm{fg} / \mu \mathrm{l}$ were produced for standard DNA preparation.

\section{qPCR}

The quantity of the target gene in the gDNA was estimated using the qPCR method. The amplification reactions contained $0.5 \mu \mathrm{M}$ nested primer pairs (Table 1), the DyNAmo HS SYBR Green master mix (Finnzyme, Espoo, Finland), and 15-25 ng gDNA or $5 \mu \mathrm{l}$ of the serially diluted standard DNA. The qPCR assays were performed using an Opticon 3 thermal cycler (MJ Research, Waltham, MA, USA) with the following program: $95^{\circ} \mathrm{C}$ for $15 \mathrm{~min}, 40$ cycles of $95^{\circ} \mathrm{C}$ for $10 \mathrm{~s}, 58^{\circ} \mathrm{C}$ for $20 \mathrm{~s}$, and $72^{\circ} \mathrm{C}$ for $30 \mathrm{~s}$. The melting curve analysis was conducted by serially increasing the temperature at a rate of $0.2^{\circ} \mathrm{C}$ per $1 \mathrm{~s}$ from $45^{\circ} \mathrm{C}$ to $95^{\circ} \mathrm{C}$. The copy number of each standard DNA sample was calculated from the amount and molecular mass of the linearized plasmid using a DNA molecular weight calculator (http://www.currentprotocols.com/WileyCDA/CurPro3Tool/toolId-8.html). The $\mathrm{Ct}$ values were determined using the Opticon Monitor Software (MJ Research). The standard curve of the Ct value vs. the copy number was generated and used to calculate the total number of genome in the target gDNA template. The experiments were repeated six times, and each repetition included two technical replicates.

\section{Calculation of the genome sizes}

The genome size was estimated using two different formulas: (1) genome size $(b p)=C_{A} \times B^{-1}$, where $C_{A}$ is the mass of a single genome in picograms and $B$ is the mean mass of one nucleotide base pair $\left(1.023 \times 10^{-9} \mathrm{pg}\right)$ [30], and (2) genome size $(b p)=C_{B} \times N_{A} \times M_{B p}^{-1}$, where $C_{B}$ is the mass of a single genome in grams, $\mathrm{N}_{\mathrm{A}}$ is Avogadro's number, and $\mathrm{M}_{\mathrm{Bp}}$ is the mean molar mass of one nucleotide base pair $(660 \mathrm{~g} / \mathrm{mol})$ [27]. The genome size estimates were determined by averaging the values obtained from the formula.

\section{k-mer analysis}

NGS libraries with an insert size of 350 bp were separately prepared from $150 \mathrm{ng}$ gDNA of L. pallidum and $L$. scutellare using the TruSeq Nano DNA Sample Prep Kit (Illumina Inc., San Diego, CA, USA) following manufacturer's standard protocols. One lane of paired-end sequencing $(2 \times 101 \mathrm{bp})$ for each organism was performed using the HiSeq2000 platform (Illumina Inc.), which produced $357,940,882$ raw sequence reads for $L$. pallidum and 347,063,430 reads for L. scutellare. These raw sequence reads were subjected to pre-processing using CLC Assembly Cell (CLCBio, Arhaus, Denmark), during which the reads with a low quality score (less than Q20) were trimmed and the reads derived from duplicates or bacterial contaminations were removed.

The genome size estimation based on the k-mer frequency distribution was basically implemented as described previously (see supplementary information of [31]). In brief, 25,822,367,784 bp of high-quality reads for L. pallidum and 30,090,908,545 bp for L. scutellare were subjected to k-mer counting using the JellyFish program [32] with a k-mer size of 17 . The k-mer frequency distribution curve was plotted with the k-mer depth as the $\mathrm{x}$ axis and the k-mer frequency as the y-axis. The genome coverage depth was calculated using following formula:

Genome coverage depth $=\mathrm{k}$-mer coverage depth $\times$ average read length $\times(\text { average read length }-\mathrm{k} \text {-mer size }+1)^{-1}$, where the k-mer coverage depth is the maximal peak in the curve. The genome size was then estimated as follows:

Genome size $=$ total base number $\times(\text { genome coverage depth })^{-1}$

\section{Results and discussion}

\section{Single-copy gene cloning and standard preparation}

The PCR amplification of the cDNA from L. pallidum and L. scutellare using degenerate primers for EF1 $\alpha$ (Table 1) yielded DNA products approximately $850 \mathrm{bp}$ in size. The products were cloned, and 850-bp and 841-bp cDNA sequences were obtained from L. pallidum and L. scutellare, respectively. A BLAST search of the GenBank database using the deduced amino acid sequences as queries confirmed that the sequences were putative partial sequences of the EF1 $\alpha$ gene. The comparison of the partial sequences between L. pallidum and L. scutellare displayed 95.8\% and 98.9\% identities in the nucleotide and amino acid sequences, respectively. The comparison of the deduced amino acid sequences with those of $T$. urticae, which belongs to the same order, i.e., Trombidiformes, revealed that 
Table 2 Genome sizes of the reference arthropods estimated by the qPCR-based method

\begin{tabular}{|c|c|c|c|c|c|c|}
\hline \multirow[t]{2}{*}{ Species } & \multirow[t]{2}{*}{ Gene } & \multirow{2}{*}{$\begin{array}{l}\text { Actual size } \\
\quad(\mathrm{Mb})^{\mathrm{a}}\end{array}$} & \multicolumn{3}{|c|}{ Estimated size $(\mathrm{Mb})$} & \multirow{2}{*}{$\begin{array}{r}\text { Estimation } \\
\text { accuracy }(\%\end{array}$} \\
\hline & & & Formula from Dolezel et al. ${ }^{\mathrm{b}}$ & Formula from Wilhelm et al. ${ }^{\mathrm{b}}$ & $\overline{\text { Average }}$ & \\
\hline Drosophila melanogaster & RpS3 & 180 & $182 \pm 14$ & $195 \pm 15$ & $188 \pm 9$ & 95.1 \\
\hline Apis mellifera & RpS3 & 236 & $273 \pm 86$ & $293 \pm 92$ & $283 \pm 14$ & 79.8 \\
\hline Tetranychus urticae & RpS3 & 90 & $86 \pm 36$ & $92 \pm 39$ & $89 \pm 4$ & 98.9 \\
\hline
\end{tabular}

${ }^{a}$ Actual genome size information was obtained from references [33,34], and [35] for D. melanogaster, A. mellifera and T. urticae, respectively.

bor the formula 'Dolezel et al.' and 'Wilhelm et al.', please refer references [30] and [27], respectively.

L. pallidum and L. scutellare exhibit $87.5 \%$ and $86.2 \%$ identities, respectively. The partial gDNA fragments of $L$. pallidum (842 bp) and L. scutellare (843 bp) were amplified with gene-specific primers designed from the cDNA sequences for standard DNA preparation, and the fragments did not contain any introns.

The 438-bp and 398-bp RpS3 cDNA fragments from $L$. pallidum and L. scutellare were obtained using degenerate primers. A BLAST search using the deduced amino acid sequences showed that the partial sequences have functional domains of RpS3. The amino acid sequences of the two Leptotrombidium species were equal and showed 94.5\% identity when compared with that of T. urticae. The 448-bp gDNA fragments containing a 50-bp intron were amplified from both $L$. pallidum and L. scutellare for standard DNA preparation. For comparison to reference arthropods, the respective gDNA fragments of RpS3 gene (925 bp for D. melanogaster, $793 \mathrm{bp}$ for A. mellifera, and 629 bp for T. urticae) were obtained and cloned for standard DNA preparation.

\section{Estimation of the genome size}

The estimation of the genome sizes of the reference arthropods by qPCR using RpS3 as the target gene revealed estimated sizes of $188 \pm 9 \mathrm{Mb}, 283 \pm 14 \mathrm{Mb}$, and $89 \pm 4 \mathrm{Mb}$ for D. melanogaster, A. mellifera, and T. urticae, respectively (Table 2 ). These estimates were similar to the published values for the actual genome sizes (180 Mb for D. melanogaster [33], $236 \mathrm{Mb}$ for $A$. mellifera [34], and $90 \mathrm{Mb}$ for T. urticae [35]), showing the high prediction accuracy $(79.8-98.9 \%)$ and reliability of the qPCR method for genome size prediction.

The estimation of the genome size using qPCR with two single-copy genes (EF1 $\alpha$ and RpS3) of L. pallidum revealed a genome size of $185 \pm 42 \mathrm{Mb}$ and $197 \pm 47 \mathrm{Mb}$ based on the formula described by Dolezel et al. [30] and Wilhelm et al. [27], which yielded a mean estimate of $191 \pm 7 \mathrm{Mb}$ (Table 3). Similarly, the genome size of L. scutellare was estimated to be $253 \pm 22 \mathrm{Mb}$ and $271 \pm 24 \mathrm{Mb}$ using the two different formulas, respectively, which resulted in an average size estimate of $262 \pm 13 \mathrm{Mb}$ (Table 3 ).

To confirm the estimates obtained by qPCR, the genome sizes were also estimated through a k-mer analysis of the Illumina sequencing reads. The k-mer method has been successfully applied for the estimation of the genome size from NGS reads and has provided practical guidance for the design of NGS sequencing and genome assembly for several genome projects without prior knowledge of the genome size, such as the analysis of the genomes of the giant panda [36], cucumber [37], and pacific oyster [31]. Fundamentally, k-mer analysis is based solely on the sequence contents of NGS reads. Thus, if the NGS reads well represent the whole contents of the genome without any bias during the experimental procedures, including the isolation of genomic DNA, the construction of NGS libraries, and the highthroughput sequencing steps, the k-mer output should give a close estimate of the genome size.

Table 3 Genome sizes of Leptotrombidium pallidum and Leptotrombidium scutellare estimated by the qPCR and k-mer analysis-based method

\begin{tabular}{|c|c|c|c|c|c|}
\hline \multirow[t]{2}{*}{ Species } & \multirow[t]{2}{*}{ Method } & \multirow[t]{2}{*}{ Formula $^{a}$} & \multicolumn{3}{|c|}{ Estimated size $(\mathrm{Mb})$} \\
\hline & & & EF1a & $\mathrm{RpS3}$ & Average \\
\hline \multirow[t]{4}{*}{ Leptotrombidium pallidum } & & Dolezel et al. & $155 \pm 42$ & $215 \pm 39$ & $185 \pm 42$ \\
\hline & $\mathrm{qPCR}$ & Wilhelm et al. & $164 \pm 45$ & $231 \pm 42$ & $197 \pm 47$ \\
\hline & & Average & & & $191 \pm 7$ \\
\hline & k-mer analysis & & & & 175 \\
\hline \multirow[t]{4}{*}{ Leptotrombidium scutellare } & & Dolezel et al. & $269 \pm 11$ & $237 \pm 20$ & $253 \pm 22$ \\
\hline & qPCR & Wilhelm et al. & $288 \pm 12$ & $254 \pm 22$ & $271 \pm 24$ \\
\hline & & Average & & & $262 \pm 13$ \\
\hline & k-mer analysis & & & & 286 \\
\hline
\end{tabular}

a For the formula 'Dolezel et al.' and 'Wilhelm et al.', please refer references [30] and [27], respectively. 


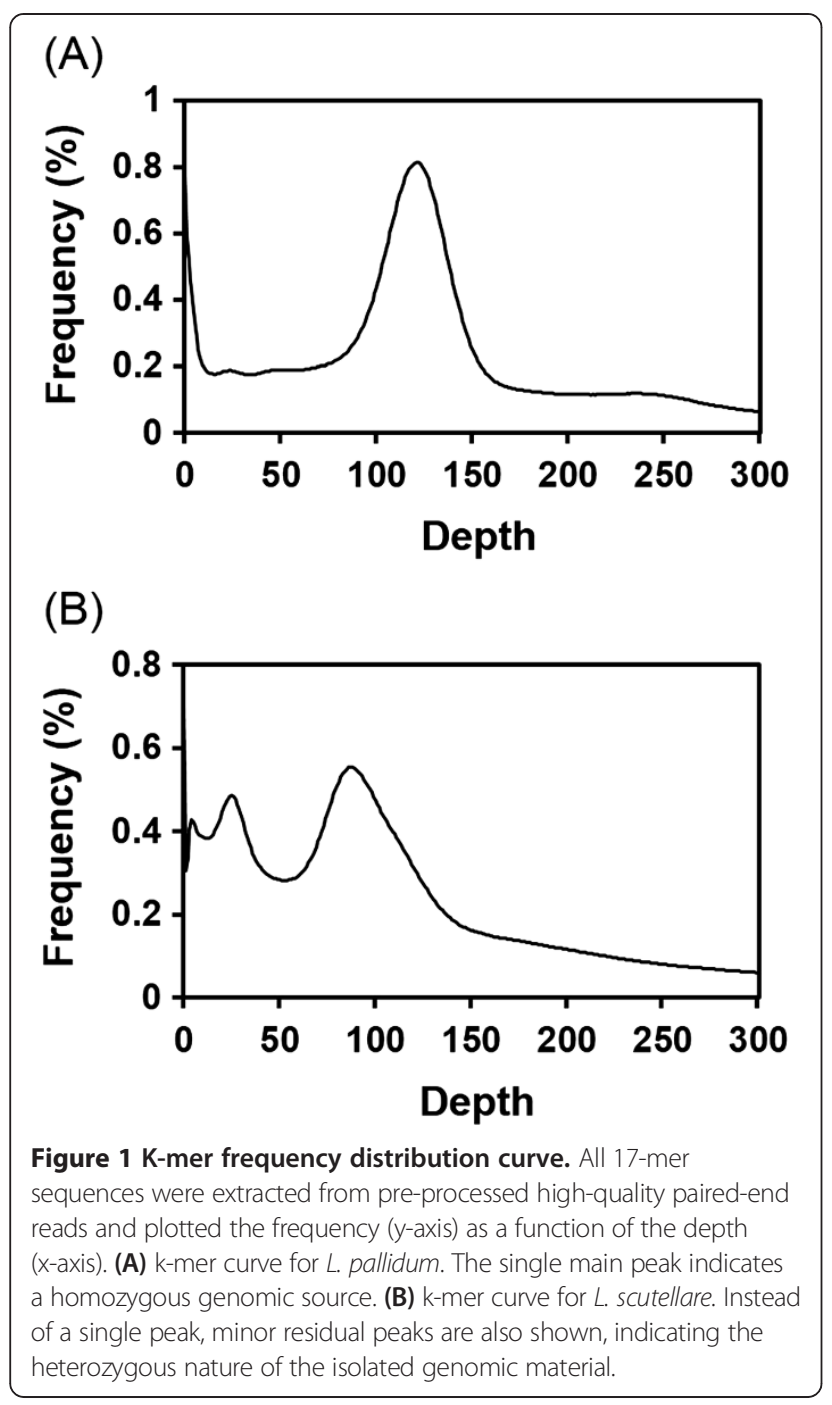

The resulting values obtained from the k-mer analysis were $175 \mathrm{Mb}$ for L. pallidum and $286 \mathrm{Mb}$ for L. scutellare (Figure 1). Compared with the values obtained by qPCR, the estimates obtained for L. pallidum and L. scutellare based on k-mer analysis were $16-\mathrm{Mb}$ smaller and $24-\mathrm{Mb}$ larger, respectively. The smaller L. pallidum genome size based on the k-mer analysis compared with the qPCR estimate (i.e., $175 \mathrm{Mb}$ vs. $191 \mathrm{Mb}$ ) may be the result of the omission of parts of the genome, such as heterochromatic regions or highly repetitive regions, during the NGS process. In contrast, for L. scutellare, the k-mer estimate was larger than the qPCR estimate (i.e., $286 \mathrm{Mb}$ vs. $262 \mathrm{Mb}$ ). The k-mer frequency curve showed the existence of minor residual peaks, which indicates that there may be genomic contamination or a certain level of heterozygosity in the genomic pool of $L$. scutellare (Figure 1). Nevertheless, the calculation of the mean values between these two methods revealed that the genome sizes of L. pallidum and L. scutellare were $183 \mathrm{Mb}$ and $274 \mathrm{Mb}$, respectively. The mean deviations accounted for only $8.7 \%$ and $8.8 \%$ of the respective mean genome size estimates between the two methods, suggesting that these estimates are mutually complementary.

Interestingly, the estimated genome size of $L$. scutellare appears to be approximately 1.5 -fold larger than that of L. pallidum even though they belong to the same Leptotrombidium genus. Because both species have very similar biology and ecology, this genome size difference is not likely due to a difference in the gene numbers but rather to differences in the non-coding sequences. A similar genome size difference between closely related species within the same genus was reported in the comparison of D. melanogaster and $D$. virilis: the euchromatic genome size of D. virilis $(150 \mathrm{Mb})$ was $36 \%$ larger than that of $D$. melanogaster $(110 \mathrm{Mb})$, and this difference was well correlated with the significant increase in the intron size [38]. Similarly, genome size differences are also found in several arthropod

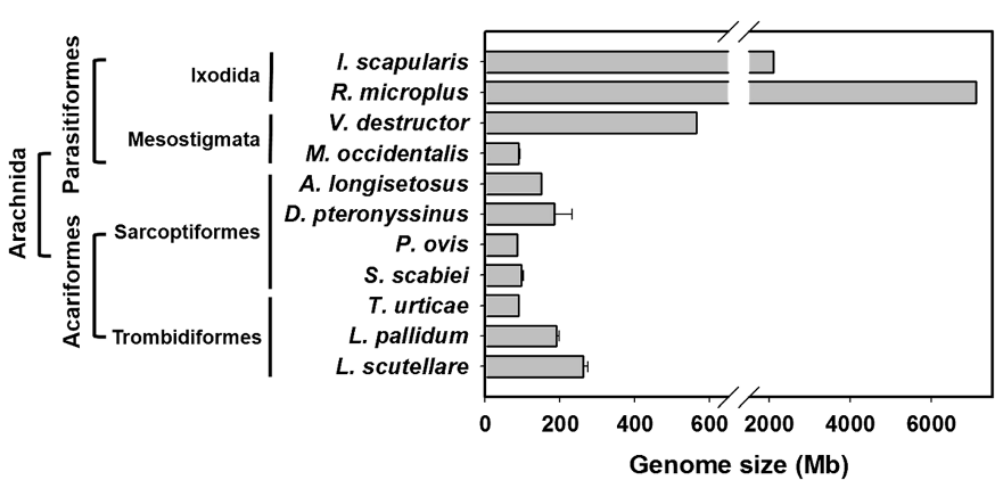

Figure 2 Comparison of the genome sizes of arachnids. The genome sizes of 11 arachnids in 4 orders, Ixodes scapularis [41], Rhipicephalus microplus [41], Varroa destructor [42], Metaseiulus occidentalis [26], Archegozetes longisetosus [39], Dermatophagoides pteronyssinus, Psoroptes ovis, Sarcoptes scabiei [25], Tetranychus urticae [35], Leptotrombidium pallidum and Leptotrombidium scutellare, were compared. 
species within the same genus: the genome estimates of Pseudacteon tricuspis $(746 \mathrm{Mb}$ ) and P. obtusus (613 Mb) showed a $20 \%$ difference, the estimated genome size of Calosoma scrutator $(1,019 \mathrm{Mb})$ was $39 \%$ larger than that of C. sayi $(732 \mathrm{Mb})$, and Polistes exclamans (542 Mb) has a 44\% larger genome than P. Carolina (376 Mb) [39].

There are a variety of other factors that may result in an increase in genome size, including increases in the copy number of transposable elements, the amount of simple repeated sequences, the size of inter-enhancer spacers, the amount or size of microsatellites, and the presence of large numbers of pseudogenes (reviewed by [40]).

The comparison of the estimated genome sizes with those of other mites or ticks revealed that the estimates are larger than those of $T$. urticae $(90 \mathrm{Mb}$ ), which belongs to the same order (Trombidiformes), S. scabiei (96 $\pm 7 \mathrm{Mb}$ ) [25], and P. ovis $(86 \pm 2 \mathrm{Mb})$ [25]. However, the estimated genome sizes are similar to those of other Acariformes mites and markedly smaller than those of Parasitiformes ticks, such as Ixodes scapularis $(2.1 \mathrm{~Gb})$ and Rhipicephalus microplus (7.1 Gb) [41] (Figure 2). Although the C-value paradox is also applicable for the various genome sizes across the major groups of mites and ticks within the subclass Acari, the relatively smaller genome sizes of mites compared to those of true ticks appear to be positively correlated with their smaller cellular or nuclear sizes (i.e., smaller body sizes).

\section{Conclusions}

In this study, the genome sizes of the scrub typhus vectors L. pallidum and L. scutellare were estimated using the qPCR-based calculation and k-mer analysis. The determined sizes were $183 \mathrm{Mb}$ for L. pallidum and 274 Mb for L. scutellare. Although flow cytometry could not be performed due to the limited genetic material, the results from the two methods were within the same range and thus likely reliable. Such relatively small genome sizes should enable a more successful analysis of the whole genomes of these chigger mites even based on NGS, and the genome size estimates may serve as firm reference values for the genome assembly following sequencing.

Starting with the I. scapularis genome project, which was the first in the subphylum Chelicerata, several studies have attempted to obtain genomic information for arachnids, such as Varroa destructor [42], Boophilus microplus [43], Metaseiulus occidentalis [44], and Tetranychus urticae [35]. In addition to the previous studies, the genome sequencing of Leptotrombidium mites may contribute to the understanding of mite vector biology, Arachnida genome evolution, and molecular interaction between mite vector and O. tsutsugamushi, and eventually provide key information for developing novel strategies for scrub typhus control.
Competing interests

The authors declare that they have no competing interests.

\section{Authors' contribution}

JHK, JYR, DHK, YHK, MP and SHL designed and performed the genome size estimation based on the qPCR analyses. JHK and SHL wrote the manuscript. JHK, JYR, ES and KAY maintained the laboratory strains of L. pallidum and L. scutellare. SY, S-JN and JP performed the genome size estimation using k-mer analysis. All authors read and approved the final version of the manuscript.

\section{Acknowledgments}

We are grateful to the Division of Medical Entomology at the Korea National Institute of Health for the technical support for mite collection and colony maintenance. This work was supported by a grant (2013E5500800) from the Korea National Institute of Health.

\section{Author details}

${ }^{1}$ Department of Agricultural Biotechnology, Seoul National University, Seoul 151-921, Korea. ${ }^{2}$ Division of Medical Entomology, National Institute of Health, Osong 363-951, Korea. ${ }^{3}$ Research Institute of Agriculture and Life Sciences, Seoul National University, Seoul 151-921, Korea. ${ }^{4}$ Deparment of Research, Codes Division, Insilicogen, Inc, Suwon 441-813, Korea.

Received: 18 April 2014 Accepted: 11 June 2014

Published: 20 June 2014

\section{References}

1. Kawamura A, Tanaka H: Rickettsiosis in Japan. Jpn J Exp Med 1988, 58(4):169-184

2. Tamura A: Tsutsugamushi disease and Rickettsia tsutsugamushi especially on the transmission process and antigenic variation of the Rickettsia. Jpn J Tox Env Health 1995, 41(3):179-193.

3. Kelly DJ, Fuerst PA, Ching WM, Richards AL: Scrub typhus: the geographic distribution of phenotypic and genotypic variants of Orientia tsutsugamushi. Clin Infect Dis 2009, 48:S203-S230.

4. Lerdthusnee K, Khlaimanee N, Monkanna T, Sangjun N, Mungviriya S, Linthicum KJ, Frances SP, Kollars TM, Coleman RE: Efficiency of Leptotrombidium chiggers (Acari: Trombiculidae) at transmitting Orientia tsutsugamushi to laboratory mice. J Med Entomo/ 2002, 39(3):521-525.

5. Kumar D, Raina D, Gupta S, Angurana A: Epidemiology of scrub typhus. JK Sci 2010, 12:60-62.

6. Eamsobhana P, Yoolek A, Kongkaew W, Lerdthusnee K, Khlaimanee N, Parsartvit A, Malainual N, Yong HS: Laboratory evaluation of aromatic essential oils from thirteen plant species as candidate repellents against Leptotrombidium chiggers (Acari: Trombiculidae), the vector of scrub typhus. Exp Appl Acarol 2009, 47(3):257-262

7. Ree H-I, Lee I-Y, Cho M-K: Determination of the vector species of tsutsugamushi disease in Korea. Korean J Parasitol 1991, 29(1):87-92.

8. Seong SY, Choi MS, Kim IS: Orientia tsutsugamushi infection: overview and immune responses. Microbes Infect 2001, 3(1):11-21.

9. Rapmund G: Rickettsial diseases of the Far-east - New perspectives. $J$ Infect Dis 1984, 149(3):330-338.

10. Oaks S, Ridgway R, Shirai A, Twartz J: Scrub typhus. Malaysia Institute for Medical Research: Kuala Lumpur; 1983.

11. Takada N: Recent findings on vector acari for rickettsia and spirochete in Japan. Jpn J Sanit Zool 1995, 46:91.

12. Chang WH: Current status of tsutsugamushi disease in Korea. J Korean Med Sci 1995, 10(4):227.

13. Kim DM, Kim K, Nam H, Kweon S, Park MY, Ryu S: Risk-factors for human infection with Orientia tsutsugamushi: a case-control study in Korea. Clin Microbiol Infec 2008, 14(2):174-177.

14. Takahashi M, Misumi H, Urakami H, Nakajima S, Furui S, Yamamoto S, Furuya Y, Misumi M, Matsumoto I: Mite vectors (Acari: Trombiculidae) of scrub typhus in a new endemic area in northern Kyoto. Japan J Med Entomol 2004, 41(1):107-114.

15. Zhang SY, Song HB, Liu Y, Li Q, Wang Y, Wu JB, Wan JF, Li GL, Yu CJ, Li XY, Yin WW, Xu Z, Liu B, Zhang Q, Wan KL, Li GC, Fu XP, Zhang JS, He JR, Hai R, Yu DZ, Walker DH, Xu JG, Yu XJ: Scrub typhus in previously unrecognized areas of endemicity in China. J Clin Microbiol 2010, 48(4):1241-1244. 
16. Shirai A, Tanskul P, Andre R, Dohany A, Huxsoll D: Rickettsia tsutsugamushi strains found in chiggers collected in Thailand. Southeast Asian J Trop Med Public Health 1981, 12(1):1.

17. Shirai A, Dohany A, Ram S, Chiang G, Huxsoll D: Serological classification of Rickettsia tsutsugamushi organisms found in chiggers (Acarina: Trombiculidae) collected in Peninsular Malaysia. Trans $R$ Soc Trop Med Hyg 1981, 75(4):580-582.

18. Uchikawa K, Kawamori F, Kanda T, Kumada N: Trombiculid fauna and seasonal abundance of Leptotrombidium scutellare (Acari, Trombiculidae) in an endemic area of scrub typhus (tsutsugamushi disease) in Yamakita town. Kanagawa prefecture Japan J Med Entomol 1994, 31(6):844-849.

19. Houck MA, Qin H, Roberts HR: Hantavirus transmission: potential role of ectoparasites. Vector-Borne Zoonot 2001, 1(1):75-79.

20. Kabeya H, Colborn JM, Bai Y, Lerdthusnee K, Richardson JH, Maruyama S, Kosoy MY: Detection of Bartonella tamiae DNA in ectoparasites from rodents in Thailand and their sequence similarity with bacterial cultures from Thai patients. Vector-Borne Zoonot 2010, 10(5):429-434.

21. Collins F, Lander E, Rogers J, Waterston R, Conso I: Finishing the euchromatic sequence of the human genome. Nature 2004, 431(7011):931-945.

22. Cho NH, Kim HR, Lee JH, Kim SY, Kim J, Cha S, Kim SY, Darby AC, Fuxelius HH, Yin J, Kim JH, Kim J, Lee SJ, Koh YS, Jang WJ, Park KH, Andersson SGE, Choi MS, Kim IS: The Orientia tsutsugamushi genome reveals massive proliferation of conjugative type IV secretion system and host-cell interaction genes. Proc Natl Acad Sci U S A 2007, 104(19):7981-7986.

23. Marescalchi O, Scali V, Zuccotti M: Genome size in parental and hybrid species of Bacillus (Insecta, Phasmatodea) from southeastern Sicily - a flow cytometric analysis. Genome 1990, 33(6):789-793.

24. DeSalle R, Gregory TR, Johnston JS: Preparation of samples for comparative studies of arthropod chromosomes: Visualization, in situ hybridization, and genome size estimation. Method Enzymol 2005, 395:460-488.

25. Mounsey KE, Willis C, Burgess STG, Holt DC, McCarthy J, Fischer K: Quantitative PCR-based genome size estimation of the astigmatid mites Sarcoptes scabiei. Psoroptes ovis and Dermatophagoides pteronyssinus. Parasite Vectors 2012, 5:3.

26. Jeyaprakash A, Hoy MA: The nuclear genome of the phytoseiid Metaseiulus occidentalis (Acari: Phytoseiidae) is among the smallest known in arthropods. Exp Appl Acarol 2009, 47(4):263-273.

27. Wilhelm J, Pingoud A, Hahn M: Real-time PCR-based method for the estimation of genome sizes. Nucleic Acids Res 2003, 31(10):e56.

28. Gao J, Scott JG: Use of quantitative real-time polymerase chain reaction to estimate the size of the house-fly Musca domestica genome. Insect Mol Biol 2006, 15(6):835-837.

29. Park B, Kim Y: Genome size estimation of an endoparasitoid wasp, Cotesia plutellae, using quantitative real-time polymerase chain reaction. J Asia-Pac Entomol 2012, 15(3):349-353.

30. Dolezel J, Bartos J, Voglmayr H, Greilhuber J: Nuclear DNA content and genome size of trout and human. Cytom Part A 2003, 51A(2):127-128.

31. Zhang GF, Fang XD, Guo XM, Li L, Luo RB, Xu F, Yang PC, Zhang LL, Wang XT, Qi HG, Xiong ZQ, Que HY, Xie YL, Holland PWH, Paps J, Zhu YB, Wu FC, Chen YX, Wang JF, Peng CF, Meng J, Yang L, Liu J, Wen B, Zhang N, Huang ZY, Zhu QH, Feng Y, Mount A, Hedgecock D, et al: The oyster genome reveals stress adaptation and complexity of shell formation. Nature 2012, 490(7418):49-54

32. Marcais G, Kingsford C: A fast, lock-free approach for efficient parallel counting of occurrences of k-mers. Bioinformatics 2011, 27(6):764-770.

33. Adams MD, Celniker SE, Holt RA, Evans CA, Gocayne JD, Amanatides PG, Scherer SE, Li PW, Hoskins RA, Galle RF, George RA, Lewis SE, Richards S, Ashburner M, Henderson SN, Sutton GG, Wortman JR, Yandell MD, Zhang Q, Chen LX, Brandon RC, Rogers YHC, Blazej RG, Champe M, Pfeiffer BD, Wan $\mathrm{KH}$, Doyle C, Baxter EG, Helt G, Nelson CR, et al: The genome sequence of Drosophila melanogaster. Science 2000, 287(5461):2185-2195.

34. Weinstock GM, Robinson GE, Gibbs RA, Worley KC, Evans JD, Maleszka R, Robertson HM, Weaver DB, Beye M, Bork P, Elsik CG, Hartfelder K, Hunt GJ, Zdobnov EM, Amdam GV, Bitondi MMG, Collins AM, Cristino AS, Lattorff HMG, Lobo CH, Moritz RFA, Nunes FMF, Page RE, Simoes ZLP, Wheeler D, Carninci P, Fukuda S, Hayashizaki Y, Kai C, Kawai J, et al: Insights into social insects from the genome of the honeybee Apis mellifera. Nature 2006, 443(7114):931-949.

35. Grbic M, Van Leeuwen T, Clark RM, Rombauts $S$, Rouze $P$, Grbic V, Osborne EJ, Dermauw W, Phuong CTN, Ortego F, Hernandez-Crespo P, Diaz I, Martinez M,
Navajas M, Sucena E, Magalhaes S, Nagy L, Pace RM, Djuranovic S, Smagghe G, Iga M, Christiaens O, Veenstra JA, Ewer J, Villalobos RM, Hutter JL, Hudson SD, Velez M, Yi SV, Zeng J, et al: The genome of Tetranychus urticae reveals herbivorous pest adaptations. Nature 2011, 479(7374):487-492.

36. Li RQ, Fan W, Tian G, Zhu HM, He L, Cai J, Huang QF, Cai QL, Li B, Bai YQ, Zhang ZH, Zhang YP, Wang W, Li J, Wei FW, Li H, Jian M, Li JW, Zhang ZL, Nielsen R, Li DW, Gu WJ, Yang ZT, Xuan ZL, Ryder OA, Leung FCC, Zhou Y, Cao JJ, Sun X, Fu YG, et al: The sequence and de novo assembly of the giant panda genome. Nature 2010, 463(7284):1106.

37. Huang SW, Li RQ, Zhang ZH, Li L, Gu XF, Fan W, Lucas WJ, Wang XW, Xie BY, Ni PX, Ren YY, Zhu HM, Li J, Lin K, Jin WW, Fei ZJ, Li GC, Staub J, Kilian A, van der Vossen EAG, Wu Y, Guo J, He J, Jia ZQ, Ren Y, Tian G, Lu Y, Ruan J, Qian WB, Wang MW, et al: The genome of the cucumber, Cucumis sativus L. Nat Genet 2009, 41(12):1275-U1229.

38. Vinogradov AE: Intron-genome size relationship on a large evolutionary scale. J Mol Evol 1999, 49(3):376-384.

39. Hanrahan SJ, Johnston JS: New genome size estimates of 134 species of arthropods. Chromosome Res 2011, 19(6):809-823.

40. Petrov DA: Evolution of genome size: new approaches to an old problem. Trends Genet 2001, 17(1):23-28.

41. Ullmann AJ, Lima CMR, Guerrero FD, Piesman J, Black WC: Genome size and organization in the blacklegged tick, Ixodes scapularis and the Southern cattle tick. Boophilus microplus. Insect Mol Biol 2005, 14(2):217-222.

42. Cornman SR, Schatz MC, Johnston SJ, Chen YP, Pettis J, Hunt G, Bourgeois L, Elsik C, Anderson D, Grozinger CM, Evans JD: Genomic survey of the ectoparasitic mite Varroa destructor, a major pest of the honey bee Apis mellifera. BMC Genomics 2010, 11:602.

43. Guerrero FD, Nene VM, George JE, Barker SC, Willadsen P: Sequencing a new target genome: The Boophilus microplus (Acari: Ixodidae) genome project. J Med Entomol 2006, 43(1):9-16.

44. Hoy MA: The predatory mite Metaseiulus occidentalis: mitey small and mitey large genomes. Bioessays 2009, 31(5):581-590.

\section{doi:10.1186/1756-3305-7-279}

Cite this article as: Kim et al.: Estimation of the genome sizes of the chigger mites Leptotrombidium pallidum and Leptotrombidium scutellare based on quantitative PCR and k-mer analysis. Parasites \& Vectors 2014 7:279

\section{Submit your next manuscript to BioMed Central and take full advantage of:}

- Convenient online submission

- Thorough peer review

- No space constraints or color figure charges

- Immediate publication on acceptance

- Inclusion in PubMed, CAS, Scopus and Google Scholar

- Research which is freely available for redistribution 